Annuaire suisse de politique de développement

18 | 1999

La Suisse et l'action humanitaire

\title{
Liste des pays bénéficiaires de l'aide établie par le CAD, 1997
}

\section{(2) OpenEdition Journals}

Édition électronique

URL : http://journals.openedition.org/aspd/890

DOI : 10.4000/aspd.890

ISSN : 1663-9669

Éditeur

Institut de hautes études internationales et du développement

\section{Édition imprimée}

Date de publication : 1 janvier 1999

Pagination : 261-262

ISSN : 1660-5934

\section{Référence électronique}

"Liste des pays bénéficiaires de l'aide établie par le CAD, 1997 », Annuaire suisse de politique de développement [En ligne], 18 | 1999, mis en ligne le 27 août 2012, consulté le 08 septembre 2020. URL http://journals.openedition.org/aspd/890 ; DOI : https://doi.org/10.4000/aspd.890 
PARTIE I: PAYS ET TERRITOIRES EN DÉVELOPPEMENT (AIDE PUBLIQUE AU DÉVELOPPEMENT)

PMA - Pays les moins avancés

$\begin{array}{ll}\text { Afghanistan } & \text { Guinée } \\ \text { Angola } & \text { Guinée-Bissau } \\ \text { Bangladesh } & \text { Guinée équatoriale } \\ \text { Bénin } & \text { Haïti } \\ \text { Bhoutan } & \text { Kiribati } \\ \text { Burkina Faso } & \text { Laos } \\ \text { Burundi } & \text { Lesotho } \\ \text { Cambodge } & \text { Libéria } \\ \text { Cap-Vert } & \text { Madagascar } \\ \text { Centrafricaine, Rép. } & \text { Malawi } \\ \text { Comores } & \text { Maldives } \\ \text { Congo, Rép. démocratique } & \text { Mali } \\ \text { Djibouti } & \text { Mauritanie } \\ \text { Erythrée } & \text { Mozambique } \\ \text { Ethiopie } & \text { Myanmar } \\ \text { Gambie } & \text { Népal }\end{array}$

Niger

Ouganda

Rwanda

Salomon, îles

Samoa occidentales

Sao Tomé et Principe

Sierra Leone

Somalie

Soudan

Tanzanie

Tchad

Togo

Tuvalu

Vanuatu

Yémen

Zambie

Autres PFR - Pays à faible revenu (PNB par habitant <765 dollars en 1995)

$\begin{array}{lll}{ }^{*} \text { Albanie } & \text { *Géorgie } & \text { Nicaragua } \\ { }^{*} \text { Arménie } & \text { Ghana } & \text { Nigéria } \\ { }^{*} \text { Azerbaïdjan } & \text { Guyana } & \text { Pakistan } \\ \text { Bosnie-Herzégovine } & \text { Honduras } & \text { Sénégal } \\ \text { Cameroun } & \text { Inde } & \text { Sri Lanka } \\ \text { Chine } & \text { Kenya } & \text { *Tadjikistan } \\ \text { Congo, Rép. } & { }^{*} \text { Kirghize, Rép. } & \text { Vietnam } \\ \text { Côte d'lvoire } & \text { Mongolie } & \text { Zimbabwe }\end{array}$

PRITI - Pays à revenu intermédiaire tranche inférieure (PNB par habitant 766-3035 dollars en 1995)

$\begin{array}{lll}\text { Algérie } & \text { Irak } & \text { Paraguay } \\ \text { Belize } & \text { Iran } & \text { Pérou } \\ \text { Bolivie } & \text { Jamaïque } & \text { Philippines } \\ \text { Botswana } & \text { Jordanie } & \text { St-Vincent et Grenadines } \\ \text { Colombie } & { }^{*} \text { Kazakstan } & \text { Suriname } \\ \text { Corée, Rép. démocratique } & \text { Liban } & \text { Swaziland } \\ \text { Costa Rica } & \text { Macédoine (ex-Rép. yougoslave) } & \text { Syrie } \\ \text { Cuba } & \text { Maroc } & \text { Thaïlande } \\ \text { Dominicaine, Rép. } & \text { Marshall, îles } & \text { +Timor } \\ \text { Dominique } & \text { Micronésie, Etats fédéraux } & \text { +Tokelau } \\ \text { Egypte } & { }^{*} \text { Moldavie' } & \text { Tonga } \\ \text { El Salvador } & \text { Namibie } & \text { Tunisie } \\ \text { Equateur } & \text { Niue } & * \text { Turkménistan } \\ \text { Fidji } & { }^{*} \text { Ouzbékistan } & \text { Turquie } \\ \text { Grenade } & \text { Palaos, îles } & \text { Venezuela } \\ \text { Guatemala } & \text { Panama } & \text { +Wallis et Futuna } \\ \text { Indonésie } & \text { Papouasie-Nouvelle-Guinée } & \text { Yougoslavie, Rép. féd. }\end{array}$

Zones sous administration palestinienne

* Pays d'Europe centrale et orientale (PECO) / Communauté des Etats indépendants (CEI).

1. La Moldavie a été reclassée dans la Partie I à compter du 1er janvier 1997. Jusqu'en 1996, I'aide accordée à la Moldavie est comprise dans I'Aide publique aux PECO/CEI.

+ Territoires. 
PRITS - Pays à revenu intermédiaire tranche supérieure (PNB par habitant 3036-9385 dollars en 1995)

Afrique du Sud

Croatie

Oman

+Anguilla

Gabon

Seychelles

Antigua-et-Barbuda

Lybie'

Arabie saoudite

Malaisie

Slovénie

Argentine

Malte

Bahrein

Maurice

+Ste-Hélène

Barbade

+Mayotte

Brésil

Mexique

Chili

+Montserrat

Cook, îles

Nauru

St Kitts et Nevis

Ste-Lucie

Trinité-et-Tobago

+Turks et Caïques, îles

Uruguay

PRE - Pays à revenu élevé (PNB par habitant > 9385 dollars en 1995)'

+Antilles néerlandaises

+ Gibraltar ${ }^{1}$

+Macao'

+ Aruba

Corée, Rép. ${ }^{1}$

Mariannes du Nord'

+Nouvelle-Calédonie'

+Polynésie française'

+Vierges, îles (RU)'

\section{PARTIE II: PAYS ET TERRITOIRES EN TRANSITION (AIDE PUBLIQUE)}

\begin{tabular}{|c|c|c|}
\hline *Bélarus & ${ }^{*}$ Lettonie & ${ }^{*}$ République tchèque \\
\hline *Bulgarie & *Lituanie & ${ }^{*}$ Roumanie \\
\hline *Estonie & *Pologne & ${ }^{*}$ Russie \\
\hline *Hongrie & ${ }^{*}$ République slovaque & *Ukraine \\
\hline
\end{tabular}

\section{Pays et territoires en développement plus avancés ${ }^{2}$}

$\begin{array}{lll}\text { Bahamas } & \text { Chypre } & \text { Israël } \\ \text { +Bermudes } & \text { Emirats arabes unis } & \text { Koweït } \\ \text { Brunei } & \text { +Falkland, îles } & \text { Oatar } \\ \text { +Caïmans, îles } & \text { +Hong-Kong, Chine } & \text { Singapour } \\ & & \text { Taipei chinois }\end{array}$

Remarques: Nous nous conformons pour l'établissement de cette liste à la classification adoptée par le CAD de l'OCDE.

Selon la politique adoptée par le CAD en 1993, la liste des bénéficiaires de l'aide établie par le CAD est composé de deux parties. Les examens périodiques, suivant des critères établis, peuvent conduire au fait que certains pays bénéficiaires soient transférés d'une partie à une autre, notamment de la Partie I à la Partie II (voir le rapport Co-opération pour le développement, 1996, p. A101).

Les statistiques qui figurent dans ce rapport incluent les dernières données pour l'année 1996, et reflètent ainsi la liste du CAD telle qu'elle était en 1996. La liste présentée ci-dessus prend effet à partir du 1'r janvier 1997. Les notes cidessus expliquent entre autres les différences entre les listes en 1996 et en 1997.

Source: Rapport 1997 du CAD, OCDE.

1. Tous ces pays et territoires seront reclassés parmi les pays plus avancés le 1er janvier 2000, à moins qu'une exception soit décidée.

2. Les pays bénéficiaires indiqués en italique figuraient sur la Partie I de la Liste du CAD jusqu'à la fin de 1996. Jusqu'en 1996, I'aide accordée à ces pays est comprise dans l'Aide publique au développement aux Pays à revenu élevé. Ils ont été reclassés dans la Partie I| le 1" janvier 1997. Les autre pays bénéficiaires qui figurent dans ce tableau ont été reclassés dans la Partie II à compter du 1* janvier 1996. Jusqu'en 1995, l'aide accordée à ces pays est comprise dans l'Aide publique au développement aux Pays à revenu élevé.

+ Territoires.

* Pays d'Europe centrale et orientale (PECO) / Communauté des Etats indépendants (CEI). 